\section{Freeze Tolerance of Nine Zoysiagrass Cultivars Using Natural Cold Acclimation and Freeze Chambers}

\author{
Jason D. Hinton \\ Department of Crop Science, North Carolina State University, $4123 \mathrm{~A}$ \\ Williams Hall, Campus Box 27695, Raleigh, NC 27695 \\ David P. Livingston III \\ U.S. Department of Agriculture and Department of Crop Science, North \\ Carolina State University, Raleigh, NC 27695
}

Grady L. Miller ${ }^{1}$ and Charles H. Peacock

Department of Crop Science, North Carolina State University, 4123 A Williams Hall, Campus Box 27695, Raleigh, NC 27695

\section{Tan Tuong}

U.S. Department of Agriculture and Department of Crop Science, North Carolina State University, Raleigh, NC 27695

Additional index words. Zoysia japonica, Zoysia matrella, $\mathrm{LT}_{50}$, turfgrass

\begin{abstract}
Winter-hardiness of zoysiagrass (Zoysia spp.) cultivars is an important attribute throughout the biogeographical transition zone; thus, the inability to withstand freezing temperatures may limit the use of these cultivars. The objective of this research was to determine the freeze tolerance $\left(\mathrm{LT}_{50}\right)$ of nine zoysiagrass cultivars grown in Raleigh, NC. Four Zoysia japonica Steud. cultivars (JaMur, Palisades, Empire, and Ultimate) and five Zoysia matrella (L.) Merr. cultivars (Pristine, Zeon, Cavalier, Diamond, and Zorro) were chosen to undergo freeze testing. Cores were taken from the field in Feb. 2008, 2009, and 2010 for the winter trials and in Apr. 2008, 2009, and 2010 for the spring trials (after green-up had occurred). The cores were subjected to freeze treatments of $-6,-8,-10,-12$, and $-14^{\circ} \mathrm{C}$ in programmable freezers. After thawing, cores were placed in a $41 / 20^{\circ} \mathrm{C}$ greenhouse to promote green-up. Cores were rated for green-up after 4 weeks on a 1 to 9 scale. Nonlinear regression analysis was used to calculate an $\mathbf{L T}_{\mathbf{5 0}}$ value for each cultivar. 'JaMur', 'Palisades', 'Empire', and 'Ultimate' were no different in the winter trials with an $\mathbf{L T}_{\mathbf{5 0}}$ ranging from $\mathbf{- 9 . 8}$ to $10.2^{\circ} \mathrm{C}$. Among the matrella species, 'Zeon', 'Cavalier', and 'Zorro' were no different but 'Diamond' ( $\mathrm{LT}_{50}$ of $-6.0^{\circ} \mathrm{C}$ ) and 'Pristine' $\left(\mathrm{LT}_{50}\right.$ of $\left.-5.7^{\circ} \mathrm{C}\right) \mathrm{had}$ less tolerance to freezing than the other matrella cultivars $\left(\mathrm{LT}_{\mathbf{5 0}}\right.$ range from $\mathbf{- 9 . 7}$ to $\left.\mathbf{- 9 . 8}\right)$, suggesting lower ability to cold-acclimate in the field than the other cultivars. Shoot weights of cores were correlated to visual green-up ratings for each cultivar with an $R^{2}$ range from 0.70 to 0.99 indicating a good relationship between the green-up ratings and shoot weights.
\end{abstract}

Japanese Lawn Grass (Zoysia japonica Steud.) and Manilagrass [Zoysia matrella (L.) Merr.] are high-quality warm-season turfgrasses used on golf courses, athletic fields, and lawns (Beard, 1973). This is partially the result of their better cold tolerance than most bermudagrass [Cynodon dactylon (L.) Pers.] cultivars (Anderson et al., 2002; Patton and Reicher, 2007). Susceptibility to winter injury is a major characteristic to consider when deciding which turfgrass species and cultivar to use. The selection of the best grass for different environments is crucial to creating superior turf. Areas of turf loss resulting from freeze stress could lead to re-establishment

Received for publication 30 Aug. 2011. Accepted for publication 27 Nov. 2011.

${ }^{1}$ To whom reprint requests should be addressed; e-mail grady_miller@ncsu.edu. influences their ability to recover from turf loss. Differences in establishment rate (Patton and Reicher, 2005), divot recovery (Karcher et al., 2006), and shade tolerance (Sladek et al., 2009) have been reported and could be related to recovery from winter damage.

Winter survival of genotypes under field conditions is a good indicator of freezing tolerance However, year-to-year variability in temperatures cold enough to differentiate the freezing tolerance of genotypes makes successful field testing a lengthy process. Dunn et al. (1999a) indicates that it may take as many as 10 years for maximum separation of cultivars for the determination of winterhardiness under natural conditions. The use of freeze chambers can help determine winterhardiness in a more timely fashion. The objectives of this research were to determine the $\mathrm{LT}_{50}$ of zoysiagrass cultivars that were naturally cold-acclimated in a field setting. In addition to winter freezing tolerance, the same cultivars were measured during spring greenup to determine their ability to withstand a late spring freeze. Knowledge of late spring freeze performance is particularly important when growing turfgrasses in the transition zone of the United States.

\section{Materials and Methods}

Nine commercially available cultivars of $Z$. japonica and $Z$. matrella were selected for a study of freezing tolerance. Plots of four $Z$. japonica cultivars and four Z. matrella cultivars were established from sod in Aug. 2007 (one additional Z. matrella cultivar was added in 2008) at the North Carolina State University Lake Wheeler Turf Field Laboratory, in Raleigh, NC. The soil at this site is classified as a Cecil sandy loam (Fine, kaolinitic, thermic Typic Kanhapludults). The $Z$. japonica cultivars were JaMur (Doguet, 2002a), Palisades (Engelke et al., 2002c), Empire (Ito and Gurgel, 2000), and Ultimate. The $Z$. matrella cultivars were Pristine (Scully et al., 2009), Zeon (Doguet, 2002b), Cavalier (Engelke et al., 2002b), and Diamond (Engelke et al., 2002a). Additionally, a cultivar of Z. matrella, Zorro (Engelke and Reinert, 2003), was established from sod in May 2008. The $Z$. japonica cultivars were mowed once weekly at a height of $2.5 \mathrm{~cm}$ using a rotary mower and the $Z$. matrella cultivars were mowed twice a week at a height of $1.3 \mathrm{~cm}$ using a reel mower. All plots were fertilized with a total nitrogen rate of $171 \mathrm{~kg} / \mathrm{ha} /$ year split between five application dates. A complete fertilizer $(16 \mathrm{~N}-1.8 \mathrm{P}-6.6 \mathrm{~K})$ was applied in early spring and sulfur-coated urea $(42 \mathrm{~N}-0 \mathrm{P}-0 \mathrm{~K})$ was used for the other four applications.

The cultivars were cold-acclimated under field conditions before cores were extracted in the winter trials. The grasses were extracted after green-up in the spring trials to simulate a late freeze. Plugs were taken from each cultivar on 5 Feb. 2008, 24 Feb. 2009, and 23 Feb. 2010 for the winter trials for maximize acclimation and 15 Apr. 2008, 27 Apr. 2009, and 27 Apr. 2010 for the spring trials after full green-up. The plugs were $5 \mathrm{~cm} \times 5 \mathrm{~cm} \times 2.5 \mathrm{~cm}$ 
deep from the soil surface. The plugs were stored in a cold chamber at $3{ }^{\circ} \mathrm{C}$ for no longer than $2 \mathrm{~d}$ before applying freeze treatments. The low-temperature exposure treatments were $-6,-8,-10,-12$, and $-14{ }^{\circ} \mathrm{C}$ for the winter trials and the 2008 spring trial and $-4,-6,-8$, -10 , and $-12{ }^{\circ} \mathrm{C}$ for the 2009 and 2010 spring trials. The 2008 trials did not include 'Zorro'. The plugs were placed in plastic bags with a small amount of ice to initiate freezing and to prevent supercooling. Four plugs of each cultivar were randomly placed in a programmable freezer set at $-3{ }^{\circ} \mathrm{C}$ in the dark for each temperature treatment. Thermocouples were inserted into several plugs in each freezer to monitor internal plug temperature; the plugs took $\approx 13 \mathrm{~h}$ to reach $-3{ }^{\circ} \mathrm{C}$. After reaching $-3{ }^{\circ} \mathrm{C}$, the freezers were cooled at a rate of $1{ }^{\circ} \mathrm{C} \cdot \mathrm{h}^{-1}$ until the target temperature was reached. The target temperature was held for $3 \mathrm{~h}$ and then increased at a rate of $2{ }^{\circ} \mathrm{C} \cdot \mathrm{h}^{-1}$ until reaching $3{ }^{\circ} \mathrm{C}$ ( $\mathrm{Li}$ et al., 2010; Livingston et al., 2005). Unfrozen, control plugs at $3{ }^{\circ} \mathrm{C}$ were placed in a dark container and kept in the cold chamber. After the frozen plugs were thawed and reached $3{ }^{\circ} \mathrm{C}$, they were removed from the freezers and planted into $10.2-\mathrm{cm}$ diameter pots filled with Metro-Mix 200 (2008 trials) growing medium from SUNGRO or Fafard 4P Mix (2009 and 2010 trials) growing medium from Conrad Fafard, Inc. The pots were arranged in a greenhouse in a randomized complete block design. The greenhouse had high/low temperatures of $41 / 20{ }^{\circ} \mathrm{C}$ and overhead irrigation set to run three times per day to supply $0.75 \mathrm{~cm}$ water. Supplemental lighting was provided by $1000-\mathrm{W}$ metal halide lamps $\left(350 \mu \mathrm{mol} \cdot \mathrm{m}^{-2} \cdot \mathrm{s}^{-1}\right)$ to simulate a daylength of $16 \mathrm{~h}$. The plugs were maintained in the greenhouse for $28 \mathrm{~d}$.

The plugs were visually rated for greenup after $28 \mathrm{~d}$ on a 1 to 9 scale with 1 meaning no live shoots and 9 meaning excellent shoot growth similar to unfrozen controls. The plug green-up ratings were used to determine freeze tolerance or $\mathrm{LT}_{50}$, the temperature at which no regrowth occurs in $50 \%$ of the plants, through nonlinear regression using an equation adopted from Ingram and Buchanan (1984) and used by Patton and Reicher (2007) and also Anderson et al. (2002). The $\mathrm{LT}_{50}$ was calculated using the equation:

$$
\begin{aligned}
\text { Greenup }= & \mathrm{Y}_{\min }+\left(\mathrm{Y}_{\max }-\mathrm{Y}_{\min }\right) \\
& /\left\{1+\exp \left[\mathrm{k}\left(\mathrm{T}_{\text {mid }}-\mathrm{T}\right)\right]\right\}
\end{aligned}
$$

where $Y_{\min }$ is the baseline of green-up, $Y_{\max }$ is the maximum green-up, $\mathrm{k}$ is a function of the slope of the line at the inflection point, $\mathrm{T}_{\text {mid }}$ is the inflection point temperature $\left(\mathrm{LT}_{50}\right)$, and $\mathrm{T}$ is the temperature of the treatment. PROC NLIN (Gauss-Newton method) was used to fit the data to sigmoidal curves and the resulting $\mathrm{LT}_{50}$ values were analyzed for means separation using PROC GLM (SAS Institute, Cary, NC). Figure 1 shows the sigmoidal curves for both the winter and spring runs of 'Zorro' and the resulting $\mathrm{LT}_{50}$ values.

Shoot dry weights were taken for the 2010 trials by clipping the live shoots after 4 weeks'

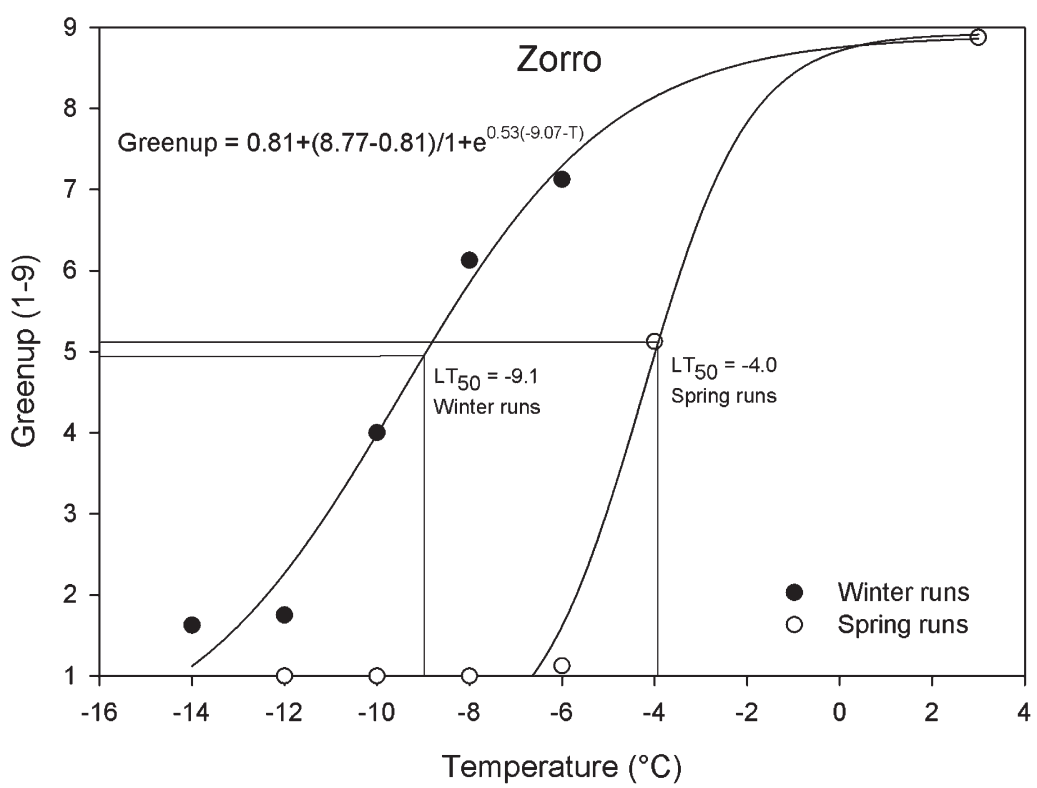

Fig. 1. Sigmoidal curve fit to visual green-up ratings of 'Zorro' zoysiagrass for both winter and spring runs.

growth in the greenhouse from each plug and oven-drying the clippings. The dry shoot weights were then plotted against the visual green-up data to determine the correlation between the two ratings for each cultivar. Quadratic, polynomial, nonlinear regression was calculated with SigmaPlot (Version 11.0; Systat Software, Inc., San Jose, CA) using the equation: $\mathrm{y}=\mathrm{y}_{\mathrm{o}}+\mathrm{ax}+\mathrm{bx}^{2}$. Regression predictability and correlation are closely related, so the coefficient of determination $\left(R^{2}\right)$, the proportionate reduction in error for regression (Ott and Longnecker, 2001), can determine if the shoot weights correlate with the visual ratings.

\section{Results and Discussion}

Not surprisingly, freezing tolerance was greatly influenced by the time of year or season that the plugs were taken from the field plots (Tables 1 and 2). As a result of a difference in mowing height used for each species, results were presented separately by species (Table 2). All the cultivars tested were significantly more freezing-tolerant when plugs were taken in the winter than in the spring. The $\mathrm{LT}_{50}$ for the cultivars during the winter trials ranged from $-5.6^{\circ} \mathrm{C}$ for Pristine to $-10.5^{\circ} \mathrm{C}$ for 'Empire', whereas the cultivars during the spring trials ranged from $-3.5^{\circ} \mathrm{C}$ for 'Pristine' and 'Diamond' to $-4.6{ }^{\circ} \mathrm{C}$ for 'JaMur' (Table 2). The lower freezing tolerance of plugs taken in the spring suggests that considerable deacclimation had occurred as seasons shifted and indicates that a spring freeze would cause significant damage in all the cultivars. It is possible that 'JaMur' may have slightly more spring freeze tolerance than the other cultivars but that could not be statistically demonstrated under these conditions.

A recording of daily minimum air temperature for the years 2008 through 2010
Table 1. Mean square from combined analysis of variance for green-up ratings of zoysiagrasses.

\begin{tabular}{lrc}
\hline Source of variation & \multicolumn{1}{c}{ df } & Mean square \\
\hline Cultivar (C) & 8 & $77.1^{* *}$ \\
Rep (R) & 3 & 1.3 \\
Temp (T) & 6 & $1415.6^{* *}$ \\
Year (Y) & 2 & $9.1^{*}$ \\
Season (year) [S (Y)] & 3 & $594.3^{* *}$ \\
$\mathrm{C} \times \mathrm{T}$ & 48 & $11.7^{* *}$ \\
$\mathrm{C} \times \mathrm{Y}$ & 15 & 3.4 \\
$\mathrm{C} \times \mathrm{S}(\mathrm{Y})$ & 23 & $19.9^{* *}$ \\
Error & 1139 & 2.4 \\
$\mathrm{CV}, \%$ & & 42.3 \\
\hline
\end{tabular}

*, **Significance at $P \leq 0.05$ and $P \leq 0.01$, respectively.

Table 2. Freeze tolerance $\left(\mathrm{LT}_{50}\right)$ of zoysiagrass cultivars that were naturally cold-acclimated and frozen under controlled conditions.

\begin{tabular}{lcc}
\hline & \multicolumn{2}{c}{$\mathrm{LT}_{50}\left({ }^{\circ} \mathrm{C}\right)^{\mathrm{y}}$} \\
\cline { 2 - 3 } Cultivar & Winter runs $^{\mathrm{x}}$ & Spring runs $^{\mathrm{w}}$ \\
\hline Z. japonica & $-10.2 \mathrm{a}$ & $-4.6 \mathrm{~b}$ \\
JaMur & $-9.6 \mathrm{a}$ & $-4.2 \mathrm{ab}$ \\
Palisades & $-10.5 \mathrm{a}$ & $-4.2 \mathrm{ab}$ \\
Empire & $-9.8 \mathrm{a}$ & $-3.9 \mathrm{a}$ \\
Ultimate & 1.2 & 0.6
\end{tabular}

\begin{tabular}{lcc} 
Z. matrella & & \\
Pristine & $-5.6 \mathrm{a}$ & $-3.5 \mathrm{a}$ \\
Zeon & $-9.7 \mathrm{~b}$ & $-3.7 \mathrm{a}$ \\
Cavalier & $-9.8 \mathrm{~b}$ & $-3.8 \mathrm{a}$ \\
Diamond & $-6.1 \mathrm{a}$ & $-3.5 \mathrm{a}$ \\
Zorro & $-9.7 \mathrm{~b}$ & $-4.0 \mathrm{a}$ \\
LSD $_{0.05}$ & 1.4 & 0.6 \\
\hline
\end{tabular}

z'Zorro' was established May 2008 by sodding, therefore was not included in the first winter run. The other cultivars were established from sod in Aug. 2007.

${ }^{y}$ Means, within the same column and species, followed by the same letter are not significantly different $(P \leq 0.05)$.

${ }^{\mathrm{x}}$ Winter run plugs were taken on 5 Feb. 2008, 24 Feb. 2009, and 23 Feb. 2010.

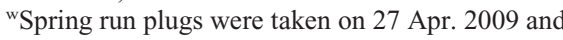
27 Apr. 2010.

LSD $=$ least significant difference 


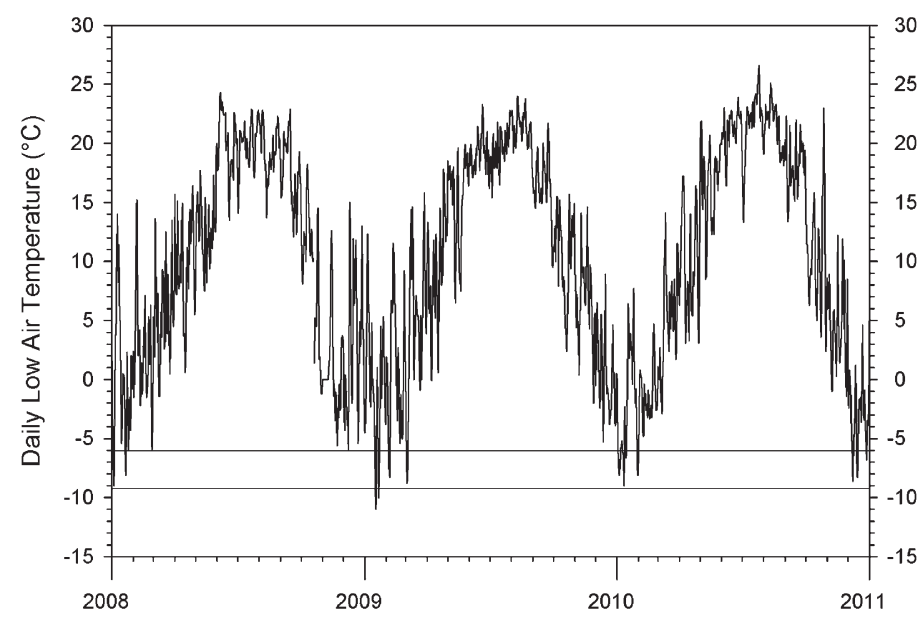

Fig. 2. Daily low air temperature $\left({ }^{\circ} \mathrm{C}\right)$ for Lake Wheeler Turf Field Laboratory in Raleigh, NC, for the years 2008, 2009, and 2010.

Table 3. Correlation of visual green-up rating to shoot dry weight for the winter and Spring 2010 runs.

\begin{tabular}{lcc}
\hline Cultivar & $R^{2}$ winter & $R^{2}$ Spring \\
\hline JaMur & 0.696 & 0.774 \\
Palisades & 0.706 & 0.936 \\
Empire & 0.760 & 0.898 \\
Ultimate & 0.808 & 0.950 \\
Pristine & 0.840 & 0.981 \\
Zeon & 0.719 & 0.995 \\
Cavalier & 0.915 & 0.938 \\
Diamond & 0.887 & 0.916 \\
Zorro & 0.880 & 0.962 \\
\hline
\end{tabular}

indicated that the temperature reached or dipped below $-6{ }^{\circ} \mathrm{C}$ over 50 times (Fig. 2) and below $-9{ }^{\circ} \mathrm{C}$ three times. This could have caused freeze damage to the most freezesensitive cultivars, but results suggest that all cultivars survived these temperature extremes (Table 2). Alternatively, these conditions could also have induced freeze acclimation (Herman et al., 2006), which would have made them more freezing-tolerant than if they had only been cold-acclimated. However, more research would be necessary to determine if zoysiagrass does, in fact, undergo freeze acclimation.

To validate green-up (survival) ratings for winter and spring freeze tests, shoot dry weight was measured and correlated with green-up ratings. The $R^{2}$ values (Table 3 ) for the winter runs ranged from 0.70 for 'JaMur' to 0.91 for 'Cavalier' and for the spring runs from 0.77 for 'JaMur' to 0.99 for 'Zeon'. The biological relevance of a difference in correlation between the winter and spring runs is not known. Both tests showed a strong relationship between visual ratings and shoot dry weight indicating that visual ratings of survival were valid.

Patton and Reicher (2007) tested four of the same zoysiagrass cultivars, Diamond, Zorro, Cavalier, and Palisades, and reported $\mathrm{LT}_{50} \mathrm{~s}$ under winter conditions that were similar or slightly lower than these. The differences they reported are likely the result of their use of a controlled acclimation procedure.
In the winter test, none of the genotypes were significantly different from each other except for 'Pristine' and 'Diamond', both of which were significantly less hardy (Table 2) than all other genotypes. In the spring test, there were no significant differences in freezing tolerance between any of the cultivars. The low level of hardiness in 'Pristine' and 'Diamond' during the winter in comparison with the other cultivars suggests that these two genotypes are missing one or more mechanisms involved in cold or freeze acclimation. More research is necessary to determine which of the numerous mechanisms (Ball et al., 2002; Cai et al., 2004; Dunn and Nelson, 1974; Guy, 1990; Hughes and Dunn, 1996; Patton et al., 2007; Thomashow, 1999; Zhang et al., 2009, 2011) that reportedly induce freezing tolerance might be missing in these cultivars.

\section{Literature Cited}

Anderson, J.A., C.M. Taliaferro, and D.M. Martin. 2002. Freeze tolerance of bermudagrasses: Vegetatively propagated cultivars intended for fairway and putting green use, and seedpropagated cultivars. Crop Sci. 42:975-977.

Ball, S., Y.L. Qian, and C. Stushnoff. 2002. Soluble carbohydrates in two buffalograss cultivars with contrasting freezing tolerance. J. Amer. Soc. Hort. Sci. 127:45-49.

Beard, J.B. 1973. Turfgrass: Science and culture Prentice-Hall, Engelwood Cliffs, NJ.

Bruneau, A.H., C.H. Peacock, and J.M. DiPaola. 1990. Effect of mowing height and fertility regimes on performance and cold tolerance of centipedegrass. Agron. Abstr. 1990:170.

Cai, Q., S. Wang, Z. Cui, J. Sun, and Y. Ishii. 2004. Changes in freezing tolerance and its relationship with the contents of carbohydrates and proline in overwintering centipedegrass. Plant Prod. Sci. 7:421-426.

Dickens, R. and W.J. Johnston. 1977. Management effects on cold tolerance of centipedegrass. Agron. Abstr. 1977:110.

DiPaola, J.M. and J.B. Beard. 1992. Physiological effects of temperature stress, p. 231-262. In: Waddington, D.V., R.N. Carrow, and R.C. Shearman (eds.). Turfgrass. Agron. Monogr. 32. ASA, CSSA, and SSSA, Madison, WI.
Doguet, D. 2002a. Zoysiagrass plant named JaMur. U.S. Plant patent 13178. 5 Nov. 2002.

Doguet, D. 2002b. Zoysiagrass plant named Zeon. U.S. Plant patent 13166. 5 Nov. 2002.

Dunn, J.H., S.S. Bughrara, M.R. Warmund, and B.F. Fresenburg. 1999a. Low temperature tolerance of zoysiagrasses. HortScience 34:9699.

Dunn, J.H., E.H. Ervin, M.R. Warmund, and B.S. Fresenburg. 1999b. Cold tolerance of zoysiagrass as influenced by cutting height and Primo. 1999 Turfgrass Research \& Information Report from the University of Missouri-Columbia Turfgrass Research Center.

Dunn, J.H. and C.J. Nelson. 1974. Chemical changes occurring in three bermudagrass turf cultivars in relation to cold hardiness. Agron. J. 66:28-31.

Engelke, M.C., P.F. Colbaugh, J.A. Reinert, K. Marcum, R.H. White, B.A. Ruemmele, and S.J. Anderson. 2002a. Registration of Diamond zoysiagrass. Crop Sci. 42:304-305.

Engelke, M.C., J.A. Reinert, P.F. Colbaugh, R.H. White, B.A. Ruemmele, K. Marcum, and S.J. Anderson. 2002b. Registration of Cavalier zoysiagrass. Crop Sci. 42:302-303.

Engelke, M.C., R.H. White, P.F. Colbaugh, J.A. Reinert, K. Marcum, B.A. Ruemmele, and S.J. Anderson. 2002c. Registration of Palisades zoysiagrass. Crop Sci. 42:305-306.

Engelke, M.C. and J.A. Reinert. 2003. Zorro zoysiagrass. U.S. Plant patent 14130. 2 Sept. 2003.

Guy, C.L. 1990. Cold-acclimation and freezing stress tolerance: Role of protein metabolism. Annu. Rev. Plant Physiol. Plant Mol. Biol. 41:187-223.

Herman, E.M., K. Rotter, R. Premakumar, G.B.R. Elwinger, L. Ehler-King, S. Chen, and D.P. Livingston, III. 2006. Additional freeze hardiness in wheat acquired by exposure to $-3{ }^{\circ} \mathrm{C}$ is correlated with changes in physiology, structure, transcriptome and proteome. J. Expt. Bot. 57:3601-3618.

Hughes, M.A. and M.A. Dunn. 1996. The molecular biology of plant acclimation to low temperature. J. Expt. Bot. 47:291-305.

Ingram, D.L. and D.W. Buchanan. 1984. Lethal high temperatures of roots of three citrus rootstocks. J. Amer. Soc. Hort. Sci. 109:189193.

Ito, M. and R.G.A. Gurgel. 2000. Zoysia grass plant named 'SS-500'. U.S. Plant patent 11466. 1 Aug. 2000.

Karcher, D., M. Richardson, J. Landreth, and J. McCalla. 2006. Variety selection affects bermudagrass and zoysiagrass divot recovery time. Golf Course Mgt. 74:83-87.

Li, R., R. Qu, A.H. Bruneau, and D.P. Livingston. 2010. Selection for freezing tolerance in St. Augustinegrass through somaclonal variation and germplasm evaluation. Plant Breed. 129: 417-421.

Livingston, D.P., III, S.P. Tallury, R. Premkumar, S.A. Owens, and C.R. Olien. 2005. Changes in the histology of cold-hardened oat crowns during recovery from freezing. Crop Sci. 45: $1545-1558$.

Ott, R.L. and M. Longnecker. 2001. An introduction to statistical methods and data analysis. Duxbury, Pacific Grove, CA.

Patton, A.J., S.M. Cunningham, J.J. Volenec, and Z.J. Reicher. 2007. Differences in freeze tolerance of zoysiagrasses: II. Carbohydrate and proline accumulation. Crop Sci. 47:2170 2181.

Patton, A.J. and Z.J. Reicher. 2005. Establishment rates of zoysiagrass cultivars, 2005 Annual 
Report: Purdue University Turfgrass Science Program. p. 1-7.

Patton, A.J. and Z.J. Reicher. 2007. Zoysiagrass species and genotypes differ in their winter injury and freeze tolerance. Crop Sci. 47:16191627.

Scully, B.T., R.T. Nagata, R.H. Cherry, L.E. Trenholm, and J.B. Unruh. 2009. Registration of Pristine zoysiagrass. J. Plant Reg. 3:65-68.
Sladek, B.S., G.M. Henry, and D.L. Auld. 2009 Evaluation of zoysiagrass genotypes for shade tolerance. HortScience 44:1447-1451.

Thomashow, M.F. 1999. Plant cold-acclimation: Freezing tolerance, genes and regulatory mechanisms. Annu. Rev. Plant Physiol. Plant Mol. Biol. 50:571-599.

Zhang, Q., J. Fry, X. Pan, C. Rajashekar, D. Bremer, M. Engelke, and X. Wang. 2009.
Acclimation of Zoysia japonica and Z. matrella and changes in rhizome abscisic acid levels. International Turfgrass Soc. Research J. 11:883892.

Zhang, X., E.H. Ervin, C. Waltz, and T. Murphy. 2011. Metabolic changes during cold acclimation and deacclimation in five bermudagrass varieties: II. Cytokinin and abscisic acid metabolism. Crop Sci. 51:847-853. 